\title{
Factors Associated with Changes in the Objectively Measured Physical Activity among Japanese Adults: A Longitudinal and Dynamic Panel Data Analysis
}

\section{Daiki Watanabe}

National Institute of Biomedical Innovation, Health and Nutrition

Haruka Murakami

Ritsumeikan University

Yuko Gando

Surugadai University

Ryoko Kawakami

Waseda University

Kumpei Tanisawa

Waseda University

Harumi Ohno

National Institute of Biomedical Innovation, Health and Nutrition

Kana Konishi

Toyo University

Azusa Sasaki

Jumonji University

Akie Morishita

Okayama Southern Institute of Health, Okayama Health Foundation

Nobuyuki Miyatake

Kagawa University

Motohiko Miyachi ( $\nabla$ cardiovascular0327@mac.com )

Waseda University

\section{Research Article}

Keywords: objectively measured physical activity, longitudinal trajectory, accelerometer, moderate to vigorous physical activity, factors of dynamic changes

Posted Date: November 19th, 2021 
DOI: https://doi.org/10.21203/rs.3.rs-1042525/v1

License: (c) (1) This work is licensed under a Creative Commons Attribution 4.0 International License. Read Full License 


\section{Abstract}

Background: Factors of dynamic changes associated with changes in the objectively measured physical activity have not been well understood. We aimed to 1) evaluate the longitudinal change in the physical activity trajectory associated with age according to sex and to 2) determine the dynamic changes factors associated with the change in physical activity-related variables across a wide age range among Japanese adults.

Methods: This longitudinal prospective study included 689 Japanese adults (3914 measurements) aged 26-85 years, whose physical activity data in at least two surveys were available. Physical activity-related variables, such as intensity (inactive, light [LPA; 1.5 to 2.9 metabolic equivalents (METs)], moderate to vigorous [MVPA; $\geq 3.0 \mathrm{METs}]$ ), total energy expenditure (TEE), physical activity level (PAL), and step count, were evaluated using a validated triaxial accelerometer. The inactive times were calculated by subtracting the sum of sedentary ( $<1.5 \mathrm{METs}$ ) and non-wearing periods from 1440 minutes. Statistical analysis involved the latent growth curve models and random-effect panel data multivariate regression analysis. The covariates for multivariate analysis included the age, sex, region, body mass index, waist/hip ratio, comorbidity score, smoking status, alcohol intake, energy intake, diet quality score, hemoglobin, heart rate, hand grips, leg power, and trunk flexibility.

Results: During a mean follow-up period of 6.8 years, physical activity was assessed 5.1 times in men and 5.9 times in women on average. The profiles for the inactive time, LPA (only men), MVPA, step count, PAL, and TEE showed clear curvature, indicating an accelerated rate of change around the age of 70 . In contrast, other variables exhibited minimal or no curvature over the age span. The MVPA trajectory was positively associated with alcohol consumption, hand grips, leg power, and trunk flexibility, and negatively associated with age, local area, BMI, comorbidity score, and heart rate over time.

Conclusions: Our results indicated that the physical activity trajectory showed clear curvature, accelerated rate of change around the age of 70 , and determined physical health and fitness and BMI as dynamic changes factors associated physical activity changes. These findings may be useful to help support populations to achieve and maintain the recommended level of physical activity.

\section{Background}

Insufficient physical activity is a leading and modifiable risk factor for a short lifespan worldwide [1, 2] and has been increasing in high-income countries over time [3]. Daily step count as an objective index of physical activity for 717,527 people in 111 countries showed heterogeneity across regions and countries [4]. The difference in physical activity between countries may explain the significant regional differences in the economic burden globally [5].

Recently, in 2020, the World Health Organization (WHO) released guidelines on physical activity and sedentary behavior to promote health [6]. Although these guidelines highlighted the importance of regularly doing moderate to vigorous-intensity physical activity (MVPA) and reducing sedentary behaviors 
in all adults [6], global estimates show that one in four (27.5\%) adults does not meet the recommendations for physical activity [3]. It is important to evaluate how physical activity changes in individuals over time because a previous study has shown decreased mean trajectory of daily step count in a short span of 2 years in older adults [7]. Some prospective cohort studies have shown that the trajectory of self-reported physical activity data is associated with a risk of mortality [8] and disability [9] in middle-aged and older adults. Therefore, there is a need to evaluate the factors associated with physical activity trajectory to increase or maintain physical activity in adults.

Many longitudinal studies have presented predictors at baseline associated with physical activity trajectory [10-12]. However, these studies cannot determine an individual's specific physical activity trajectory with the associated factors of dynamic changes. In addition, although previous longitudinal studies have verified the association between self-reported physical activity trajectory and limited timevarying variables [13-15], the factors of dynamic changes associated with objectively measured physical activity over time in adults have not been demonstrated well. These findings are essential for increasing and maintaining physical activity with the increasing spread of physical inactivity and sedentary behavior worldwide [3]. In this study, we aimed to 1) evaluate the longitudinal changes in the physical activity trajectory associated with age according to sex and 2) determine the factors of dynamic changes associated with the physical activity-related variables trajectory across a wide age range among Japanese adults. We hypothesized that physical activity may decrease with increasing age. Moreover, the factors associated with increased or decreased physical activity over time can also be determined.

\section{Methods}

\section{Study population}

This longitudinal prospective study utilized data from the cohort study, which has been described previously [16]. This cohort study had been managed by the National Institute of Health and Nutrition (NIHN) since 2007 and aimed to evaluate the association between lifestyle-related diseases and modifiable risk factors, such as dietary intake and physical activity. This cohort study included 760 adults, who agreed to participate in this study, aged 26-85 years, and lived in the Tokyo metropolitan area $(n=504)$ and Okayama prefecture $(n=256)$ in Japan from 2007 to 2018 (population density: 6168.7 people $/ \mathrm{km}^{2}$ in Tokyo and 270.1 people $/ \mathrm{km}^{2}$ in Okayama). These participants were recruited when they participated in a specific health examination conducted at the Okayama Southern Institute of Health and the NIHN. All participants were requested to participate in a health checkup conducted through an annual face-to-face meeting and a mail survey. The investigations were conducted annually using the same survey content and methodology, and the participants were followed up for a maximum of 12 years (Table S1).

Among the participants that were initially included at baseline $(n=760)$, we excluded individuals with missing data on age and sex $(n=1)$, those whose physical activity could not be measured using an accelerometer $(n=5)$, and those who completed the assessment of physical activity only once $(n=65)$. 
The final dataset included 689 participants (3914 measurements) whose physical activity information from at least two accelerometer surveys was available. Of all participants in this study, 175 individuals (25.4\% of 689 individuals) under 65 years old with a lower amount of MVPA (less than 3.3 metabolic equivalents [METs]-h/day) received an intervention composed of five-time brief counseling sessions to increase MVPA.

\section{Evaluation of physical activity}

Objective physical activity was measured using a validated triaxial accelerometer (EW4800, Panasonic Co., Ltd, Osaka, Japan) against total energy expenditure (TEE), which measured movement using both the doubly labeled water (DLW) and metabolic chamber methods [17]. Research staffs were educated on how to use and handle the accelerometer, using the manual. Participants were instructed to wear an accelerometer around the waist upon waking up till bedtime except when swimming, sleeping, and bathing. All participants were asked to wear a triaxial accelerometer for 28 days. The intensity for every minute, basal metabolic rate, step count, and physical activity level (PAL) were determined using the maker's algorithm. Wearing time was defined as 24 hours minus non-wearing and no signal time and it excluded these data with wearing time less than 6 hours per day [18]. To calculate the mean physical activity time, the sum of all physical activities surveyed over at least 7 days (including weekdays and weekends) was divided by the number of survey days.

We obtained the daily physical activity times corresponding to $<1.5$ METs (sedentary), 1.5 to 2.9 METs (light intensity physical activity: LPA), and $\geq 3.0 \mathrm{METs}$ (MVPA). The inactive times were calculated using the sum of sedentary ( $<1.5 \mathrm{METs}$ ) and non-wearing periods, which was calculated as 1440 minutes wearing periods (daily time spent in sedentary, light, moderate, and vigorous physical activity times) [16]. We included inactive time, LPA, MVPA, TEE, PAL, and step count as objective physical activity-related variables.

\section{Self-reported covariate}

Health information, such as medical history and smoking status, was obtained using self-reported structured questionnaires. Dietary intake was evaluated using the Brief-type self-administered Diet History Questionnaire (BDHQ), which consists of 58 food and beverage items that were validated against dietary records [19]. The diet quality was assessed using a previously validated Nutrition Rich Food (NRF) index 9.3 score [20]. This score ranges from 0 (worst diet quality) to 900 (best diet quality) [20]. The research staff checked all questionnaires and interviewed respondents with unanswered questions, unclear responses, or to confirm answers. Based on the data obtained regarding the comorbidity status of each individual, the comorbidity score was added to obtain a total score (including hypertension, dyslipidemia, diabetes, ischemic heart disease, other heart diseases, cerebrovascular diseases, renal failure, cancer, osteoporosis, and depression) ranging from 0 (no comorbidity) to 10 (poor status).

\section{Measured covariate}


Each participant's body weight was measured while in light clothing (BC-600, TANITA Corp., Tokyo, Japan). The body mass index (BMI) was calculated by dividing the measured body weight $(\mathrm{kg})$ by the square of the height $\left(\mathrm{m}^{2}\right)$. The waist/hip ratio was calculated as by the circumferences of the waist (at the level of the navel) to hip (the greatest posterior protuberance, perpendicular to the long axis of the trunk). Trunk flexibility was measured using a sit-and-reach digital instrument (T.K.K.5112; Takei Scientific Instruments Co., Ltd, Japan). Resting heart rate (HR) was measured using an electrocardiogram mounted on a pulse wave examination device (form PWV/ABI BP-203RPEX, Omron Colin, Kyoto, Japan).

Hemoglobin was measured using a colorimetric method that utilizes sodium lauryl sulfate from fasting blood samples ( $\geq 12$ hours). Leg press power was measured using a leg muscle strength measuring device (Anaeropress 3500, COMBI, Tokyo, Japan). This device measured the unidirectional power production of the leg extensors. Grip strength was evaluated using a Smedley Hand Dynamometer (GripD TKK5101, Takei Scientific Instruments, Niigata, Japan). Measurements were taken twice from each hand, and the mean of the highest value of each hand was used.

\section{Statistical analysis}

The participants' characteristics were expressed as a number and a percentage for categorical variables and mean and standard deviation for continuous variables. We performed imputation to missing values of covariates from five data sets, which were created using the multiple imputation method that utilizes multivariate imputation through a chained equation (MICE) by R software [21]. The details are shown in Table S1. These missing values were assumed as missing at random.

To identify the longitudinal trajectory from repeat measures of physical activity, we estimated a single mean physical activity trajectory across the group using a sex-stratified model that uses the latent growth curve models (LGCM). In addition, the latent class growth models (LCGM) were applied to assess whether study participants could be classified into multiple trajectory groups through the maximum likelihood method. These analyses were used by the STATA macro TRAJ [22], and to construct trajectory shape with a cubic specification. The best-fitting model for LCGM was identified by estimating models with 2 to 8 latent clusters and comparing them using the sample size of the clusters $(\geq 5 \%)$ and the Bayesian Information Criterion as the primary fit index [23].

To calculate the correlation coefficients by repeated measurement and cross-sectional analysis between chronological age and physical activity-related variables, we performed Repeated Measures Correlation by the R software [24] and Pearson's correlation analysis, respectively. We evaluated the accuracy and precision of the mean of the group's physical activity-related variables trajectory using previously reported equations [25]. These equations were used to estimate the required sample size and periods from withinperson variance, between-person variance, and the ratio of within-person to between-person variance.

To evaluate the factors associated with the physical activity trajectory, we used the multivariate regression analysis of random-effect panel data, which is a method that evaluates related factors from the longitudinal changes of the dependent variable and the explanatory variable to adjust the between- 
individual characteristics [26]. To evaluate factors associated with the physical activity trajectory, the multivariate analysis included the age (continuous), sex (female or male), region (urban (Tokyo) or local (Okayama)), BMI (continuous), waist/hip ratio (continuous), comorbidity score (continuous), smoking status (never smoker or past and current smoker), alcohol intake (continuous), energy intake (continuous), NRF 9.3 score (continuous), hemoglobin (continuous), HR (continuous), hand grips (continuous), leg power (continuous), and trunk flexibility (continuous). These variables were selected in reference to covariates used in previous studies [10-12, 27-29]. The results of these analyses were shown in regression coefficients $(\mathrm{RC})$ and $95 \%$ confidence interval $(\mathrm{Cl})$ for each variable per unit increment. To conduct the sensitivity analysis for results, we conducted a similar analysis using the complete cases dataset.

A two-sided $p$-value $<0.05$ was considered significant. All analyses were performed using STATA MP version 15.0 (StataCorp LP, College Station, TX, USA) and/or R software 3.4.3 (R Core Team, Vienna, Austria).

\section{Ethical considerations}

This study was conducted according to the guidelines laid down in the 1964 Declaration of Helsinki and all procedures involving research study participants were approved by the Research Ethics Committee of the National Institute of Health and Nutrition (approval no. kenei102-01). Written informed consent was obtained from all participants before data acquisition.

\section{Results}

Table 1 shows the characteristics of participants in the study cohorts. On average, the levels of physical activity-related variables were 1026 minutes/day for inactive time, 354 minutes/day for LPA, 60 minutes/day for MVPA, 10216 steps/day for step counts, 1.58 for PAL, and $1930 \mathrm{kcal} /$ day for TEE. The study participants were older than the excluded population, but a serious bias was not observed (Table S2).

Table 1. Baseline characteristics of demographic and physical activity by sex 


\begin{tabular}{|c|c|c|c|c|c|c|}
\hline \multirow[b]{2}{*}{ ears] } & \multicolumn{2}{|c|}{$\begin{array}{l}\text { Total } \\
(n=689)\end{array}$} & \multicolumn{2}{|c|}{$\begin{array}{l}\text { Men } \\
(n=212)\end{array}$} & \multicolumn{2}{|c|}{$\begin{array}{l}\text { Women } \\
(n=477)\end{array}$} \\
\hline & 52.0 & (11.6) & 49.0 & (12.0) & 53.4 & $(11.1)$ \\
\hline $\begin{array}{l}\text { area } \\
\text { a }\end{array}$ & 227 & (32.9) & 98 & $(46.2)$ & 129 & $(27.0)$ \\
\hline nass & 22.5 & (2.9) & 23.4 & $(2.7)$ & 22.1 & $(2.9)$ \\
\hline \multicolumn{7}{|l|}{$\left.{ }^{2}\right]^{b}$} \\
\hline 'Hip & 0.88 & $(0.07)$ & 0.89 & $(0.06)$ & 0.87 & $(0.07)$ \\
\hline $\begin{array}{l}\text { bidity } \\
\text { a }\end{array}$ & 524 & (76.1) & 159 & $(75.0)$ & 365 & (76.5) \\
\hline er $[n$ & 196 & $(28.4)$ & 125 & $(59.0)$ & 71 & $(14.9)$ \\
\hline $\begin{array}{l}\text { د } \\
\text { r } \\
\text { a }\end{array}$ & 501 & (72.7) & 181 & (85.4) & 320 & $(67.1)$ \\
\hline I & 1819 & (492) & 2094 & (523) & 1697 & (424) \\
\hline \multicolumn{7}{|l|}{ day] ${ }^{b}$} \\
\hline$b^{3}$ & 765 & (69) & 742 & (71) & 775 & (65) \\
\hline globin & 13.6 & (1.4) & 15.0 & $(1.0)$ & 13.0 & $(1.1)$ \\
\hline $\begin{array}{l}\text { rate } \\
b\end{array}$ & 63 & (12) & 64 & (13) & 62 & (11) \\
\hline grips & 33.5 & (9.3) & 43.2 & $(6.1)$ & 29.2 & $(6.8)$ \\
\hline Jwer & 1081 & $(410)$ & 1488 & (386) & 900 & $(266)$ \\
\hline lity & 39.1 & (9.8) & 35.9 & $(10.6)$ & 40.5 & $(9.1)$ \\
\hline \multirow{2}{*}{ day] ${ }^{b}$} & 1225 & (144) & 1346 & (161) & 1171 & (95) \\
\hline & 1930 & $(246)$ & 2040 & (305) & $\begin{array}{c}1882 \\
\text { Page } 8 / 2\end{array}$ & (195) \\
\hline
\end{tabular}


day $]^{\mathrm{b}}$

\begin{tabular}{lllllll}
\hline al & 1.58 & $(0.14)$ & 1.52 & $(0.14)$ & 1.61 & $(0.13)$ \\
$y$ & & & & & &
\end{tabular}

$\begin{array}{lllllll}\begin{array}{l}\text { ounts } \\ \text { /day] }\end{array} & 10216 & (3556) & 10528 & (3773) & 10078 & \text { (3450) }\end{array}$

$\begin{array}{llllll}\text { le } & 1026 & \text { (101) } & 1089 & \text { (93) } & 998\end{array}$

lay] ${ }^{\mathrm{b}}$

$\begin{array}{llllll}354 & (94) & 294 & (85) & 381 & (86)\end{array}$

lay $]^{\text {b }}$

$\begin{array}{llllll}60 & (27) \quad 57 & (29) & 61 & (26)\end{array}$

lay ${ }^{\text {b }}$

BMR, basal metabolic rate; LPA, low intensity physical activity; MVPA, moderate-to-vigorous physical activity; NRF, nutrient-rich food; TEE, total energy expenditure

${ }^{\text {a }}$ Categorical variables were expressed as number with (percentage).

${ }^{b}$ Continuous variables were expressed as mean with (standard deviation).

During a mean follow-up period of 6.8 years, physical activity-related variables were assessed 5.1 times ( $n=212 ; 1089$ measurements) in men and 5.9 times ( $n=477 ; 2825$ measurements) in women on average. The means of physical activity-related variables by age in both men and women in the population level are shown in Figure 1. With increasing age, the average LPA (only men), MVPA, step count, PAL, and TEE declined, while the inactive times increased. These profiles showed clear curvature, indicating an accelerated rate of change around the age of 70, whereas the LPA (only women) exhibited minimal or no curvature over the age span. Moreover, some separate trajectory groups in the physical activity-related variables were identified (Figure S1-2). These results suggest that brief counseling intervention did not affect the single mean MVPA trajectory, because the proportion of individuals in the high MVPA trajectory group in the intervention group was similar to that in the non-intervention group (Group 2 in Figure S2C: $5.1 \%$ vs $4.9 \%$ ).

We estimated correlation coefficients by repeated measurement and cross-sectional analysis between chronological age and physical activity-related variables (Figure 2). The cross-sectional analysis showed stronger correlations of TEE with chronological age compared with the repeated measurement analysis. For other variables, correlation coefficients calculated by repeated measurement and cross-sectional analysis were similar. Tables S3 shows the accuracy and precision of physical activity-related variables. 
Group sizes required for estimating a group's "true" mean physical activity related variables trajectory within a $95 \% \mathrm{Cl}$ with $2.5 \%$ deviation ranged from 63 people (PAL) to 1826 people (MVPA). Four time points of accelerometer data were required to obtain a correlation coefficient $(r)$ of 0.95 between an individual's assessed value and their "true" unevaluated usual mean physical activity-related variables.

Table 2. Factors associated with changes of physical activity times by multivariate longitudinal analysis 
Increment

effects/unit

Physical activity times ( $n=689$ [3914 measurement])

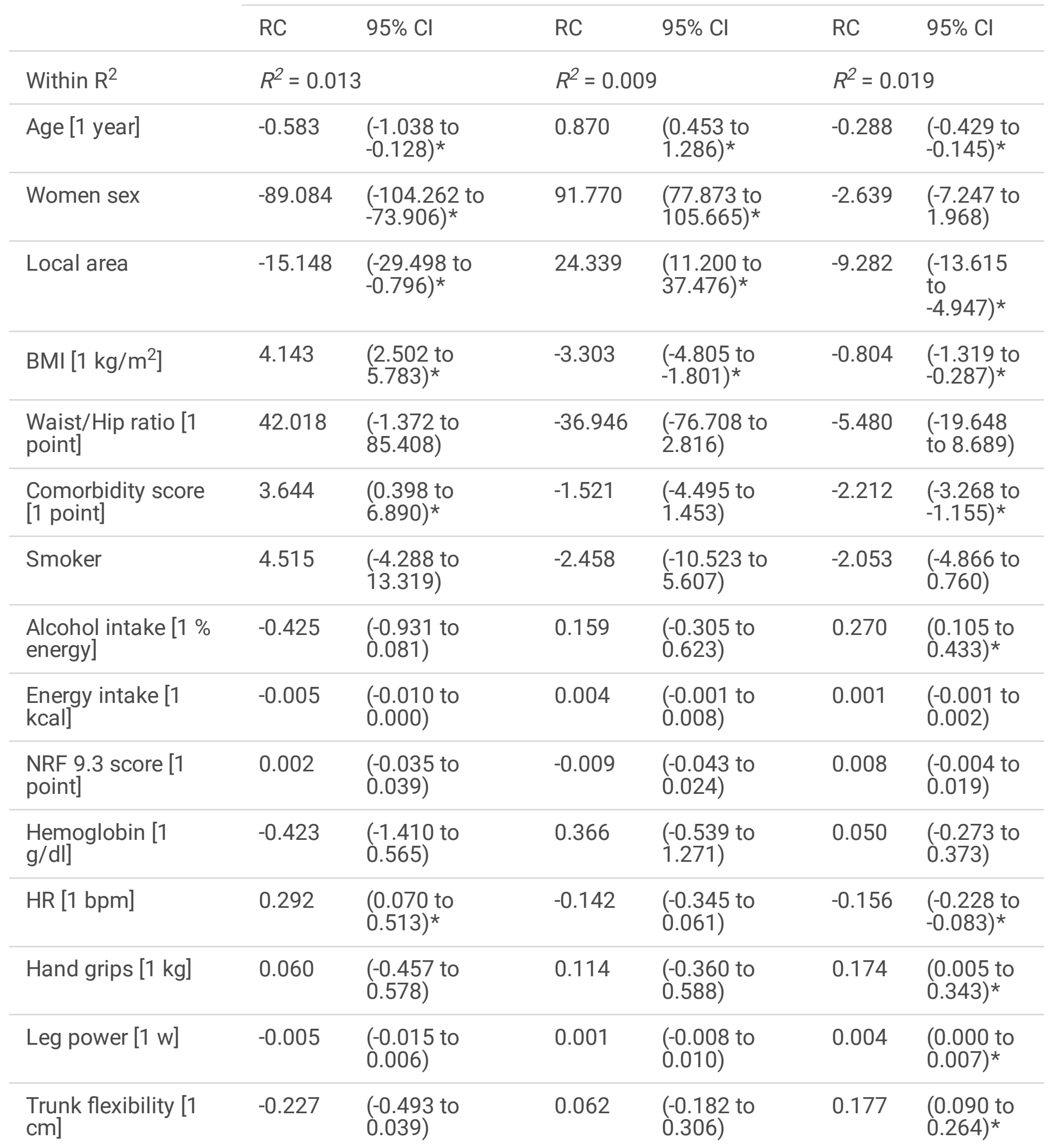

$\mathrm{BMI}$, body mass index; $\mathrm{Cl}$, confidence interval; $\mathrm{HR}$, heart rate; LPA, low intensity physical activity; MVPA, moderate-to-vigorous physical activity; NRF, nutrient-rich food; RC, regression coefficients. The results of 
these analyses are expressed as RC with $95 \% \mathrm{Cl}$. The $\mathrm{RC}$ and $95 \% \mathrm{Cl}$ were calculated for changes in physical activity-related variables per unit increment for covariates. Asterisk (*) indicates statistical significance $(p<0.05)$. Sex and area were time-stable variables, and others were time-varying variables.

Table 3. Factors associated with changes of total energy expenditure, physical activity level, and step count by multivariate longitudinal analysis 


\begin{tabular}{|c|c|c|c|c|c|c|}
\hline & \\
\hline & \multicolumn{2}{|l|}{ TEE } & \multicolumn{2}{|l|}{$\mathrm{PAL}^{\mathrm{a}}$} & \multicolumn{2}{|l|}{ Step counts } \\
\hline & $\mathrm{RC}$ & $95 \% \mathrm{Cl}$ & $\mathrm{RC}$ & $95 \% \mathrm{Cl}$ & $\mathrm{RC}$ & $95 \% \mathrm{Cl}$ \\
\hline Within $\mathrm{R}^{2}$ & \multicolumn{2}{|l|}{$R^{2}=0.016$} & \multicolumn{2}{|c|}{$R^{2}=0.015$} & \multicolumn{2}{|l|}{$R^{2}=0.079$} \\
\hline Age [1 year] & -5.677 & $\begin{array}{l}(-6.772 \text { to } \\
-4.582)^{\star}\end{array}$ & -0.012 & $\begin{array}{l}(-0.081 \text { to } \\
0.058)\end{array}$ & -89.689 & $\begin{array}{l}(-106.981 \\
\text { to }-72.396)^{*}\end{array}$ \\
\hline Women sex & -289.060 & $\begin{array}{l}(-323.048 \text { to } \\
-255.072)^{*}\end{array}$ & 7.280 & $\begin{array}{l}(5.011 \text { to } \\
9.547)^{\star}\end{array}$ & -624.138 & $\begin{array}{l}(-1182.056 \\
\text { to }-66.219)^{*}\end{array}$ \\
\hline Local area & 2.336 & $\begin{array}{l}(-29.295 \text { to } \\
33.968)\end{array}$ & 0.766 & $\begin{array}{l}(-1.366 \text { to } \\
2.898)\end{array}$ & -1847.742 & $\begin{array}{l}(-2371.96 \\
\text { to } \\
-1323.523)^{\star}\end{array}$ \\
\hline BMI [1 kg/m²] & 20.190 & $\begin{array}{l}(16.176 \text { to } \\
24.202)^{\star}\end{array}$ & -0.557 & $\begin{array}{l}(-0.810 \text { to } \\
-0.302)^{\star}\end{array}$ & -112.385 & $\begin{array}{l}(-175.195 \\
\text { to }-49.574)^{\star}\end{array}$ \\
\hline $\begin{array}{l}\text { Waist/Hip ratio [1 } \\
\text { point] }\end{array}$ & -41.811 & $\begin{array}{l}(-161.007 \text { to } \\
77.385)\end{array}$ & -8.154 & $\begin{array}{l}(-15.126 \text { to } \\
-1.182)^{\star}\end{array}$ & -2321.310 & $\begin{array}{l}(-4059.591 \\
\text { to } \\
-583.028)^{*}\end{array}$ \\
\hline $\begin{array}{l}\text { Comorbidity } \\
\text { score [1 point] }\end{array}$ & -10.486 & $\begin{array}{l}(-19.303 \text { to } \\
-1.667)^{\star}\end{array}$ & -0.719 & $\begin{array}{l}(-1.238 \text { to } \\
-0.198)^{\star}\end{array}$ & -246.592 & $\begin{array}{l}(-376.104 \\
\text { to } \\
-117.078)^{*}\end{array}$ \\
\hline Smoker & -9.186 & $\begin{array}{l}(-31.753 \text { to } \\
13.380)\end{array}$ & -1.131 & $\begin{array}{l}(-2.515 \text { to } \\
0.254)\end{array}$ & -231.790 & $\begin{array}{l}(-575.509 \\
\text { to } 111.928)\end{array}$ \\
\hline $\begin{array}{l}\text { Alcohol intake [1 } \\
\% \text { energy] }\end{array}$ & 2.176 & $\begin{array}{l}(0.831 \text { to } \\
3.521)^{\star}\end{array}$ & 0.096 & $\begin{array}{l}(0.014 \text { to } \\
0.176)^{\star}\end{array}$ & 41.491 & $\begin{array}{l}(21.441 \text { to } \\
61.541)^{\star}\end{array}$ \\
\hline $\begin{array}{l}\text { Energy intake [1 } \\
\text { kcal] }\end{array}$ & 0.017 & $\begin{array}{l}(0.002 \text { to } \\
0.030)^{\star}\end{array}$ & 0.001 & $\begin{array}{l}(0.000 \text { to } \\
0.001)^{\star}\end{array}$ & 0.096 & $\begin{array}{l}(-0.108 \text { to } \\
0.300)\end{array}$ \\
\hline $\begin{array}{l}\text { NRF } 9.3 \text { score [1 } \\
\text { point] }\end{array}$ & 0.060 & $\begin{array}{l}(-0.042 \text { to } \\
0.161)\end{array}$ & 0.004 & $\begin{array}{l}(-0.002 \text { to } \\
0.009)\end{array}$ & 1.081 & $\begin{array}{l}(-0.412 \text { to } \\
2.573)\end{array}$ \\
\hline $\begin{array}{l}\text { Hemoglobin [1 } \\
\mathrm{g} / \mathrm{dl}]\end{array}$ & 1.523 & $\begin{array}{l}(-1.213 \text { to } \\
4.259)\end{array}$ & 0.083 & $\begin{array}{l}(-0.076 \text { to } \\
0.241)\end{array}$ & -14.066 & $\begin{array}{l}(-53.766 \text { to } \\
25.634)\end{array}$ \\
\hline $\mathrm{HR}[1 \mathrm{bpm}]$ & -1.104 & $\begin{array}{l}(-1.713 \text { to } \\
-0.493)^{\star}\end{array}$ & -0.069 & $\begin{array}{l}(-0.104 \text { to } \\
-0.033)^{\star}\end{array}$ & -12.889 & $\begin{array}{l}(-21.774 \text { to } \\
-4.002)^{\star}\end{array}$ \\
\hline Hand grips [1 kg] & 1.625 & $\begin{array}{l}(0.203 \text { to } \\
3.046)^{\star}\end{array}$ & -0.056 & $\begin{array}{l}(-0.139 \text { to } \\
0.027)\end{array}$ & 34.294 & $\begin{array}{l}(6.441 \text { to } \\
62.882)^{\star}\end{array}$ \\
\hline Leg power [1 w] & 0.027 & $\begin{array}{l}(0.009 \text { to } \\
0.046)^{\star}\end{array}$ & 0.001 & $\begin{array}{l}(-0.001 \text { to } \\
0.002)\end{array}$ & 0.128 & $\begin{array}{l}(-0.297 \text { to } \\
0.554)\end{array}$ \\
\hline $\begin{array}{l}\text { Trunk flexibility [1 } \\
\mathrm{cm}]\end{array}$ & 1.424 & $\begin{array}{l}(0.694 \text { to } \\
2.153)^{\star}\end{array}$ & 0.042 & $\begin{array}{l}(-0.001 \text { to } \\
0.085)\end{array}$ & 14.008 & $\begin{array}{l}(3.334 \text { to } \\
24.681)^{*}\end{array}$ \\
\hline
\end{tabular}


$\mathrm{BMI}$, body mass index; $\mathrm{Cl}$, confidence interval; $\mathrm{HR}$, heart rate; NRF, nutrient-rich food; PAL; physical activity level; RC, regression coefficients; TEE, total energy expenditure. The results of these analyses are expressed as RC with $95 \% \mathrm{Cl}$. The RC and $95 \% \mathrm{Cl}$ were calculated for changes in physical activity-related variables per unit increment for covariates. Asterisk $\left(^{*}\right)$ indicates statistical significance $(p<0.05)$. Sex and area were time-stable variables, and others were time-varying variables.

a The RC and $95 \% \mathrm{Cl}$ shown in the estimated value corrected by the $10^{2}$ because the estimated value was small.

We evaluated the factors associated with changes in physical activity using multivariate longitudinal analysis (Table 2). The MVPA trajectory was positively associated with alcohol consumption, hand grips, leg power, and trunk flexibility, while negatively associated with age, local area, BMI, comorbidity score, and HR. Associations of TEE, PAL, and step count change with covariates are shown in Table 3. We demonstrated that the TEE was positively associated with $\mathrm{BMI}$, alcohol consumption, energy intake, hand grips, leg power, and trunk flexibility, while negatively associated with age, women, and HR. In addition, similar results were obtained for the complete cases, after excluding data with missing values, in the sensitivity analysis (Table S4,5).

\section{Discussion}

In the present study, we indicated that MVPA, step count, PAL, and TEE trajectory showed clear curvature and accelerated rate of change around the age of 70. Moreover, factors that should be encouraged or limited to improve the physical activity trajectory in Japanese adults were identified. To the best of our knowledge, this is the first study to verify the effect of physical health, fitness, and BMI on the objectively measured physical activity trajectory. These findings may potentially be useful to help increase and maintain physical activity in adults, including the elderly.

Our results demonstrate that MVPA, step count, PAL, and TEE trajectory showed clear curvature and accelerated rate of change around the age of 70 in both sexes. Some longitudinal studies have indicated that increasing age is not associated with decreasing self-reported physical activity trajectory $[10,12]$ but with decreasing objectively measured physical activity for 2 years in 70 to 90 years old men [7]. Selfreported physical activity can lead to an increase in systematic reporting bias because individuals may modify their reports in their desired direction without any actual behavior change [30]. Previous studies have reported that longitudinal growth of functional biological age accelerates at around age 70 [31], which supports our results. In addition, all individuals should not be assumed to have the same trajectory because we identified 2 to 5 different trajectory groups of physical activity-related variables. Our findings suggest that it is important to provide individuals with opportunities to be able to undertake activity education and assessment to prevent a rapid decrease in physical activity in older adults around the age of 70. Although cross-sectional studies have indicated that TEE and PAL measures using DLW methods are negatively associated with age around 60-years-old [32], these studies are limited to explaining population-level changes and cannot explain how an individual's TEE and PAL changes [33]. However, the 
triaxial accelerometer underestimated the measurements of TEE and PAL compared with those measured using the DLW technique, which is a gold standard in estimating TEE and PAL in participants with stable weight status [17]. Therefore, it is necessary to re-evaluate these results using TEE and PAL measured by the DLW method or with a more accurate accelerometer in a well-designed prospective repeated measurement study.

We indicated that there was no difference in correlation coefficients of physical activity-related variables between cross-sectional and repeated measurement; however, the cross-sectional analysis showed weaker correlations between TEE, inactive time, and LPA, as well as stronger correlations between TEE and chronological age compared with the repeated measurement analysis. Although TEE measured by DLW at baseline decreased significantly compared with that measured after 7 years in men, it did not change in women [34]. This is an important consideration since changes in fat-free mass were correlated with changes in resting metabolic rate for men but not for women [34]. In these relationships, it is possible that TEE does not substantially lower simply with increasing age because factors that change with age may be related to changes in TEE. Therefore, our results may suggest that TEE reflects the individual's LPA and inactive time changes, while the association between age and TEE was stronger while contributing to population-level changes than to individual-level changes.

Although many longitudinal studies have presented the association between predictors at baseline and physical activity [10-12], there is a need to evaluate the long-term longitudinal changes at the individual level in factors of dynamic changes associated with physical activity trajectory because an individual's habitual physical activity might be modified as time passes. Our results indicate that the MVPA trajectory was positively associated with alcohol consumption, hand grips, leg power, and trunk flexibility, while negatively associated with age, local area, BMI, comorbidity score, and HR over time. Although many previous studies have reported that higher MVPA is associated with lower body weight [35], HR [27], higher handgrips, and the lower half of the body muscle power [28], these opposite relationships have not been elucidated well [36]. It has been reported that maintaining or increasing time spent in MVPA is not beneficial to grip strength, whereas increasing grip strength increases spent time in MVPA [36]. It remains unclear whether the change in our indicated factors resulted in an increase in MVPA, because increasing MVPA may have resulted in changes in these factors. However, regardless of which comes first, a better physical activity trajectory [8] and improving these associated factors [37-39] are both important for preventing risks of all-cause and cause-specific mortality. Previous cross-sectional studies have reported that body flexibility is not associated with moderate physical activity in older adults [29]. However, we demonstrated that higher trunk flexibility was related to higher MVPA in this longitudinal study. The detailed mechanisms and causal relationships must be clarified with further intervention and basic studies. In addition, it has been shown that increasing age [7], local area [10], and comorbidity [12] are associated with lower physical activity, which supports our results. A longitudinal study of healthy older participants has reported that maintaining or increasing activity levels prevents or attenuates physiological function decline with age [40]. Therefore, it may potentially be useful to advise on healthy behavior and factor changes based on our findings to help increase and maintain physical activity or physiological function in adults.

Page 15/22 
The strength of the present study is the objective measurement of repetitive physical activity and covariates using a validated tool in the same population. This approach provides an opportunity to determine the association of changes in different parameters of dynamic changes associated with physical activity trajectory across a wide age range. We were able to minimize the influence of confounders derived from interindividual variance by using the repeated data described above. However, the present study has certain methodological limitations. First, the participants may be more healthconscious than the general Japanese population because we could not include study participants by a random sampling method. In fact, several thousands more daily step counts were observed in the present study than in National Health and Nutrition Examination Survey in Japan examined by random sampling [41]. In addition, the participant's characteristics, such as age and physical activity including step count and LPA, differed from those of individuals who were excluded from the present study. Therefore, the present study may have a selection bias. Second, this study had a relatively short follow-up period, and this might have influenced the physical activity trajectory. However, the sample size and frequency of surveys required for our group's mean physical activity trajectory were adequate. Third, we were unable to completely eliminate confounding factors and measurement bias. Although we examined economic and medication status, we could not use these variables as covariates due to incomplete data. These limitations may affect the generalization of our results. Therefore, a well-designed longitudinal cohort study with larger randomized samples is required in the future to further determine the factors of dynamic changes associated with changes in the objectively measured physical activity

\section{Conclusion}

Our results indicate that MVPA, step count, PAL, and TEE trajectory show clear curvature and accelerated rate of change around the age of 70 . Moreover, these determined physical health, fitness, and $\mathrm{BMI}$ as factors of dynamic changes associated with physical activity changes. Given the insufficient physical activity and heterogeneity of physical activity across regions and countries, there is an urgent need to highlight the importance of improving factors associated with greater beneficial effects for increasing physical activity worldwide. Therefore, these results may provide useful insights into the development of effective strategies for increasing physical activity.

\section{Abbreviations}

BDHQ, brief-type self-administered diet history questionnaire; BMI, body mass index; $\mathrm{Cl}$, confidence interval; LCGM, latent class growth models; LGCM, latent growth curve models; LPA, light intensity physical activity; METs, metabolic equivalents; MVPA, moderate to vigorous intensity physical activity; NIHN, National Institute of Health and Nutrition; NRF9.3, Nutrient-Rich Food Index 9.3; PAL, physical activity level; TEE, total energy expenditure;

\section{Declarations}

\section{Ethics approval and consent to participate}


This study was conducted according to the guidelines laid down in the 1964 Declaration of Helsinki and all procedures involving research study participants were approved by the Research Ethics Committee of the National Institute of Health and Nutrition (approval no. kenei102-01). Written informed consent was obtained from all participants before data acquisition.

\section{Consent for publication}

Not applicable.

\section{Availability of data and materials}

The datasets used and analysed during the current study are available from the corresponding author on reasonable request (cardiovascular0327@mac.com).

\section{Competing interests}

The authors declare that they have no competing interests.

\section{Funding}

This study was supported by a Grant-in-Aid for Scientific Research (C) (JP16K00944; to M. Miyachi) for the purpose of designing the study, and for data collection and analysis.

\section{Authors' contributions}

DW, MM formulated the research questions and designed the study; $H M, Y G, R K, K T, H O, K K, A S, A M, N M$, MM obtained the data; DW analyzed the data, designed research and wrote paper; DW, MM drafted the manuscript; HM, YG, RK, KT, HO, KK, AS, AM, NM provided critical feedback; MM had primary responsibility for final contents; and all authors read and approved the final manuscript.

\section{Acknowledgements}

We are grateful to all of the participants who provided data for use in this research and to the members of the Physical Activity Research Laboratory at the National Institute of Health and Nutrition. The authors thank Dr. Michiya Tanimoto, Dr. Noriko Tanaka, Dr. Hiroshi Kawano, Dr. Kenta Yamamoto, Dr. Motoyuki lemitsu, Dr. Kiyoshi Sanada, , Ms. Yumi Ohmori, Ms. Rie Katayama, Dr. Zhenbo Cao, Ms. Eriko Kubo, Ms. Miyuki Hayashi, Mr. Satoshi Hanawa, Ms. Naeko Kurose, Ms. Aiko Hirosako, Ms. Sayaka Nakamura, Ms. Hidemi Hara, Ms. Miki Yoshida, Dr. Satoshi Kurita, Ms. Noriko Wada, Ms. Miho Okamoto, Ms. Hisako Ito, Ms. Kinue Nakajima, Ms. Kaori Sato, and Ms. Kazumi Kajiwara, who significantly contributed to the realization of this cohort study through their long-term involvement as research assistants.

\section{References}


1. Collaborators GBDRF: Global burden of 87 risk factors in 204 countries and territories, 1990-2019: a systematic analysis for the Global Burden of Disease Study 2019. Lancet 2020, 396(10258):12231249.

2. Strain T, Brage S, Sharp SJ, Richards J, Tainio M, Ding D, Benichou J, Kelly P: Use of the prevented fraction for the population to determine deaths averted by existing prevalence of physical activity: a descriptive study. Lancet Glob Health 2020, 8(7):e920-e930.

3. Guthold R, Stevens GA, Riley LM, Bull FC: Worldwide trends in insufficient physical activity from 2001 to 2016: a pooled analysis of 358 population-based surveys with 1.9 million participants. Lancet Glob Health 2018, 6(10):e1077-e1086.

4. Althoff T, Sosic R, Hicks JL, King AC, Delp SL, Leskovec J: Large-scale physical activity data reveal worldwide activity inequality. Nature 2017, 547(7663):336-339.

5. Ding D, Lawson KD, Kolbe-Alexander TL, Finkelstein EA, Katzmarzyk PT, van Mechelen W, Pratt M, Lancet Physical Activity Series 2 Executive C: The economic burden of physical inactivity: a global analysis of major non-communicable diseases. Lancet 2016, 388(10051):1311-1324.

6. Bull FC, Al-Ansari SS, Biddle S, Borodulin K, Buman MP, Cardon G, Carty C, Chaput JP, Chastin S, Chou $\mathrm{R}$ et al: World Health Organization $\mathbf{2 0 2 0}$ guidelines on physical activity and sedentary behaviour. $\mathrm{Br} \mathrm{J}$ Sports Med 2020, 54(24):1451-1462.

7. Jefferis BJ, Sartini C, Ash S, Lennon LT, Wannamethee SG, Lee IM, Whincup PH: Trajectories of objectively measured physical activity in free-living older men. Med Sci Sports Exerc 2015, 47(2):343349 .

8. Mok A, Khaw KT, Luben R, Wareham N, Brage S: Physical activity trajectories and mortality: population based cohort study. BMJ 2019, 365:12323.

9. Artaud F, Sabia S, Dugravot A, Kivimaki M, Singh-Manoux A, Elbaz A: Trajectories of Unhealthy Behaviors in Midlife and Risk of Disability at Older Ages in the Whitehall II Cohort Study. J Gerontol A Biol Sci Med Sci 2016, 71(11):1500-1506.

10. Barnett TA, Gauvin L, Craig CL, Katzmarzyk PT: Distinct trajectories of leisure time physical activity and predictors of trajectory class membership: a 22 year cohort study. Int J Behav Nutr Phys Act 2008, 5:57.

11. Kiviniemi AM, Perkiomaki N, Auvinen J, Herrala S, Hautala AJ, Ahola R, Tammelin T, Tulppo MP, Jarvelin MR, Korpelainen R et al: Lifelong Physical Activity and Cardiovascular Autonomic Function in Midlife. Med Sci Sports Exerc 2016, 48(8):1506-1513.

12. Pettee Gabriel K, Sternfeld B, Colvin A, Stewart A, Strotmeyer ES, Cauley JA, Dugan S, KarvonenGutierrez C: Physical activity trajectories during midlife and subsequent risk of physical functioning decline in late mid-life: The Study of Women's Health Across the Nation (SWAN). Prev Med 2017, 105:287-294.

13. Aggio D, Papachristou E, Papacosta O, Lennon LT, Ash S, Whincup PH, Wannamethee SG, Jefferis BJ: Trajectories of self-reported physical activity and predictors during the transition to old age: a 20-year cohort study of British men. Int J Behav Nutr Phys Act 2018, 15(1):14. 
14. Laddu DR, Wertheim BC, Garcia DO, Brunner R, Groessl E, Shadyab AH, Going SB, LaMonte MJ, Cannell B, LeBoff MS et al: Associations Between Self-Reported Physical Activity and Physical Performance Measures Over Time in Postmenopausal Women: The Women's Health Initiative. J Am Geriatr Soc 2017, 65(10):2176-2181.

15. Pan LY, Hsu HC, Chang WC, Luh DL: Trajectories of physical activity and risk factors among Taiwanese older adults. Int J Behav Med 2015, 22(1):62-69.

16. Gando Y, Yamamoto K, Murakami H, Ohmori Y, Kawakami R, Sanada K, Higuchi M, Tabata I, Miyachi M: Longer time spent in light physical activity is associated with reduced arterial stiffness in older adults. Hypertension 2010, 56(3):540-546.

17. Murakami H, Kawakami R, Nakae S, Nakata Y, Ishikawa-Takata K, Tanaka S, Miyachi M: Accuracy of Wearable Devices for Estimating Total Energy Expenditure: Comparison With Metabolic Chamber and Doubly Labeled Water Method. JAMA Intern Med 2016, 176(5):702-703.

18. Tudor-Locke C, Camhi SM, Troiano RP: A catalog of rules, variables, and definitions applied to accelerometer data in the National Health and Nutrition Examination Survey, 2003-2006. Prev Chronic Dis 2012, 9:E113.

19. Kobayashi S, Honda S, Murakami K, Sasaki S, Okubo H, Hirota N, Notsu A, Fukui M, Date C: Both comprehensive and brief self-administered diet history questionnaires satisfactorily rank nutrient intakes in Japanese adults. J Epidemio/2012, 22(2):151-159.

20. Murakami K, Livingstone MBE, Fujiwara A, Sasaki S: Reproducibility and Relative Validity of the Healthy Eating Index-2015 and Nutrient-Rich Food Index 9.3 Estimated by Comprehensive and Brief Diet History Questionnaires in Japanese Adults. Nutrients 2019, 11(10).

21. Buuren SV, Groothuis-Oudshoorn K: mice: Multivariate Imputation by Chained Equations in R. Journal of Statistical Software 2011, 45(3):1-67.

22. Jones BL, Nagin DS: Note on a Stata Plugin for Estimating Group-based Trajectory Models. Sociological Methods \& Research 2013, 42:1-6.

23. Zheng W, Mu J, Chu C, Hu J, Yan Y, Ma Q, Lv Y, Xu X, Wang K, Wang Y et al: Association of Blood Pressure Trajectories in Early Life with Subclinical Renal Damage in Middle Age. J Am Soc Nephrol 2018, 29(12):2835-2846.

24. Bakdash JZ, Marusich LR: Repeated Measures Correlation. Front Psycho/ 2017, 8:456.

25. Watanabe D, Yoshida T, Watanabe Y, Yamada Y, Kimura M, Group KS: Objectively Measured Daily Step Counts and Prevalence of Frailty in 3,616 Older Adults. J Am Geriatr Soc 2020, 68(10):23102318.

26. Baltagi BH, Kao C: Nonstationary Panels, Cointegration in Panels and Dynamic Panels: A Survey. Center for Policy Research 2000, 136.

27. Reimers AK, Knapp G, Reimers CD: Effects of Exercise on the Resting Heart Rate: A Systematic Review and Meta-Analysis of Interventional Studies. J Clin Med 2018, 7(12).

28. Ramsey KA, Rojer AGM, D'Andrea L, Otten RHJ, Heymans MW, Trappenburg MC, Verlaan S, Whittaker $A C$, Meskers CGM, Maier AB: The association of objectively measured physical activity and 
sedentary behavior with skeletal muscle strength and muscle power in older adults: A systematic review and meta-analysis. Ageing Res Rev 2021, 67:101266.

29. Stathokostas L, McDonald MW, Little RM, Paterson DH: Flexibility of older adults aged 55-86 years and the influence of physical activity. J Aging Res 2013, 2013:743843.

30. Taber DR, Stevens J, Murray DM, Elder JP, Webber LS, Jobe JB, Lytle LA: The effect of a physical activity intervention on bias in self-reported activity. Ann Epidemio/2009, 19(5):316-322.

31. Li X, Ploner A, Wang Y, Magnusson PK, Reynolds C, Finkel D, Pedersen NL, Jylhava J, Hagg S: Longitudinal trajectories, correlations and mortality associations of nine biological ages across 20years follow-up. Elife 2020, 9.

32. Pontzer H, Yamada Y, Sagayama H, Ainslie PN, Andersen LF, Anderson LJ, Arab L, Baddou I, BeduAddo K, Blaak EE et al: Daily energy expenditure through the human life course. Science 2021, 373(6556):808-812.

33. Kallman DA, Plato CC, Tobin JD: The role of muscle loss in the age-related decline of grip strength: cross-sectional and longitudinal perspectives. J Geronto/ 1990, 45(3):M82-88.

34. Cooper JA, Manini TM, Paton CM, Yamada Y, Everhart JE, Cummings S, Mackey DC, Newman AB, Glynn NW, Tylavsky F et al: Longitudinal change in energy expenditure and effects on energy requirements of the elderly. Nutr J 2013, 12:73.

35. Drenowatz C, Hill JO, Peters JC, Soriano-Maldonado A, Blair SN: The association of change in physical activity and body weight in the regulation of total energy expenditure. Eur J Clin Nutr 2017, 71(3):377-382.

36. Cooper A, Lamb M, Sharp SJ, Simmons RK, Griffin SJ: Bidirectional association between physical activity and muscular strength in older adults: Results from the UK Biobank study. Int J Epidemiol 2017, 46(1):141-148.

37. Yang Y, Dugue PA, Lynch BM, Hodge AM, Karahalios A, Maclnnis RJ, Milne RL, Giles GG, English DR: Trajectories of body mass index in adulthood and all-cause and cause-specific mortality in the Melbourne Collaborative Cohort Study. BMJ Open 2019, 9(8):e030078.

38. Taniguchi Y, Fujiwara Y, Murayama H, Yokota I, Matsuo E, Seino S, Nofuji Y, Nishi M, Matsuyama Y, Shinkai S: Prospective Study of Trajectories of Physical Performance and Mortality Among Community-Dwelling Older Japanese. J Gerontol A Biol Sci Med Sci 2016, 71(11):1492-1499.

39. Sharashova E, Wilsgaard T, Lochen ML, Mathiesen EB, Njolstad I, Brenn T: Resting heart rate trajectories and myocardial infarction, atrial fibrillation, ischaemic stroke and death in the general population: The Tromso Study. Eur J Prev Cardiol 2017, 24(7):748-759.

40. Rantanen T, Era P, Heikkinen E: Physical activity and the changes in maximal isometric strength in men and women from the age of 75 to 80 years. J Am Geriatr Soc 1997, 45(12):1439-1445.

41. Takamiya T, Inoue S: Trends in Step-determined Physical Activity among Japanese Adults from 1995 to 2016. Med Sci Sports Exerc 2019, 51(9):1852-1859. 
(a)

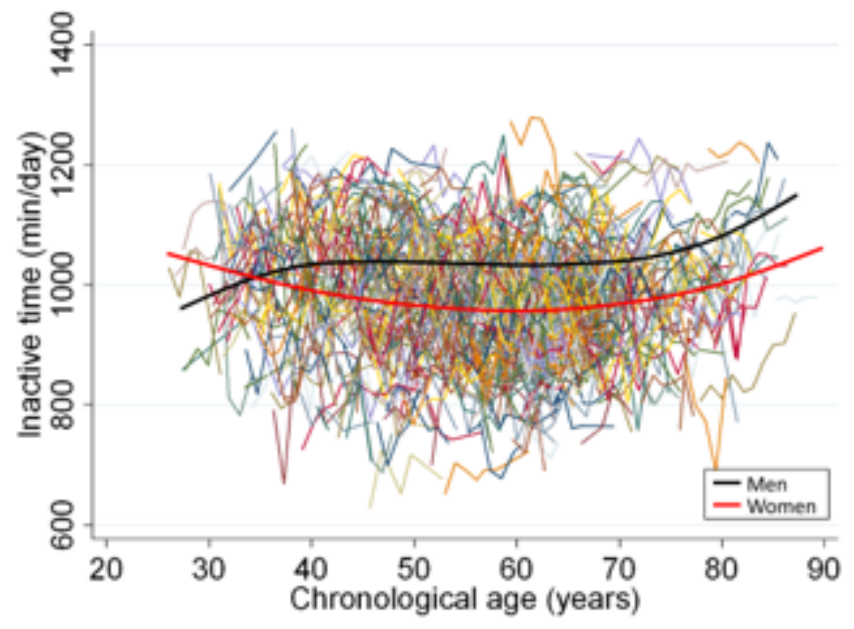

(b)

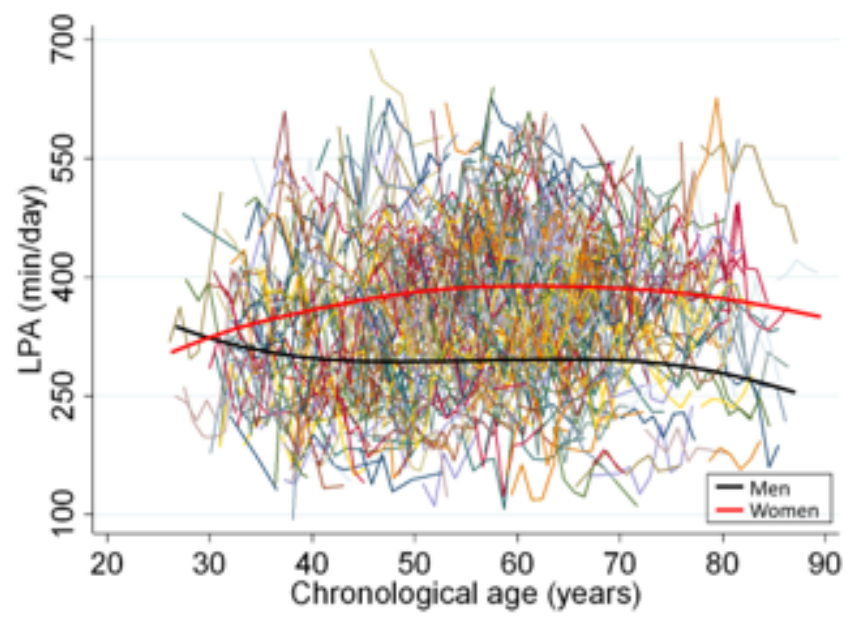

(c)

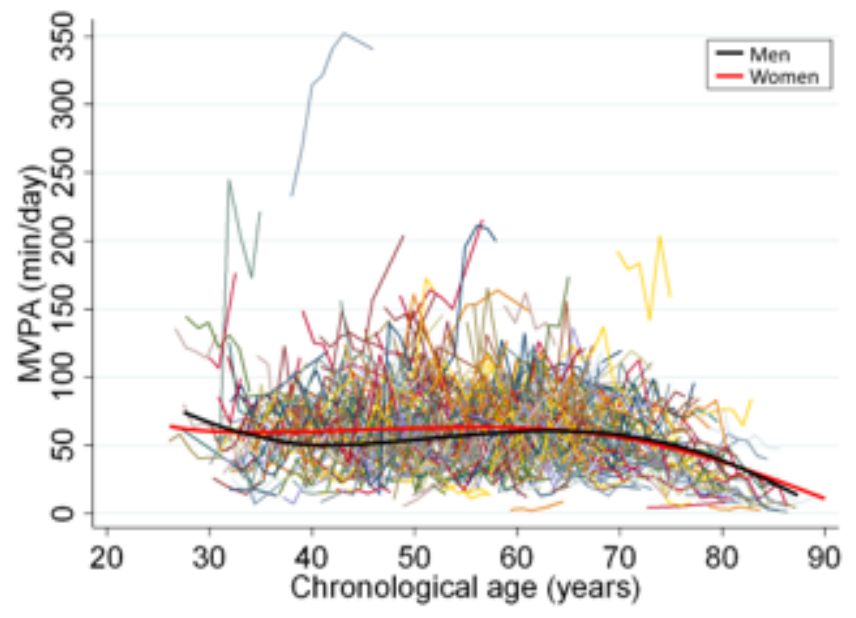

(d)

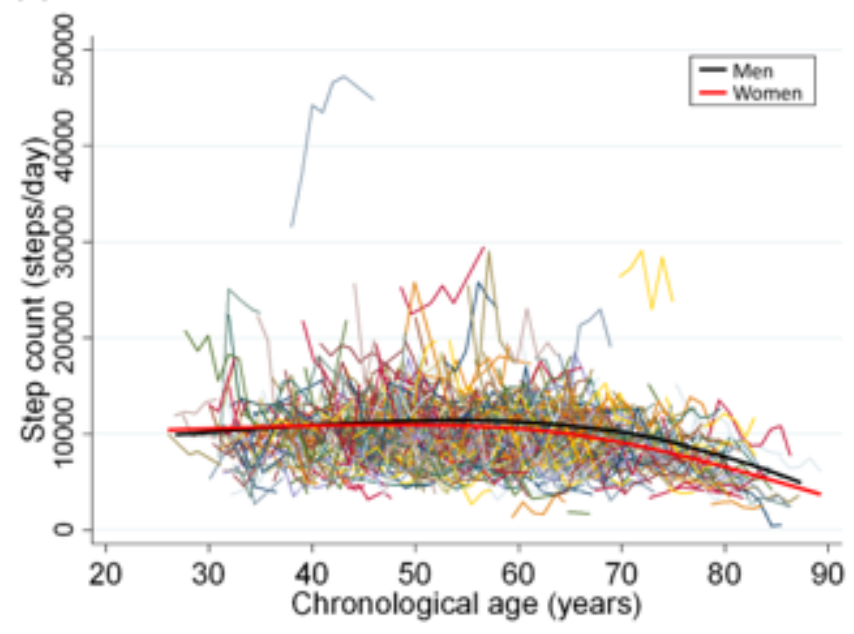

(e)

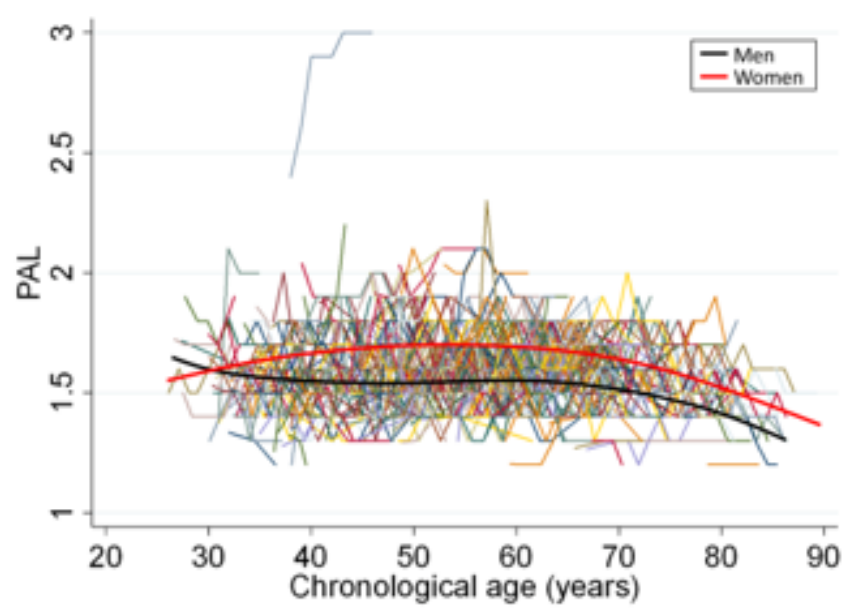

(f)

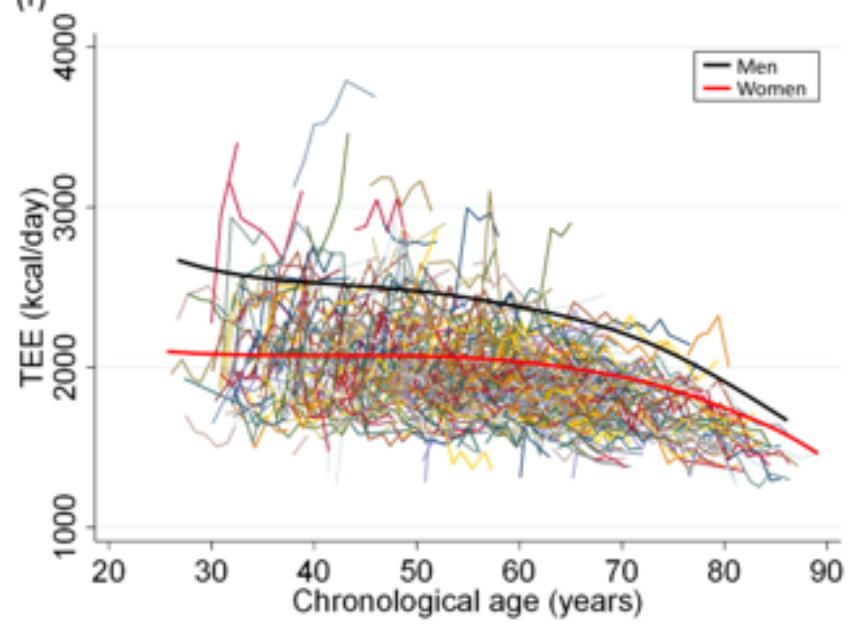

Figure 1

Longitudinal trajectories of physical activity and total energy expenditure in 689 individuals (3914 measurements) The latent growth curve models were performed to estimate a single mean (a) inactive time, (b) low-intensity physical activity (LPA), (c) moderate-to-vigorous physical activity (MVPA), (d) step count, (e) physical activity level (PAL), and (f) total energy expenditure (TEE) trajectory across the group 
by a sex-stratified model. Average changes in physical activity with age in this study population were indicated by smooth lines (black for men and pink for women).

(a) Repeated measure analysis

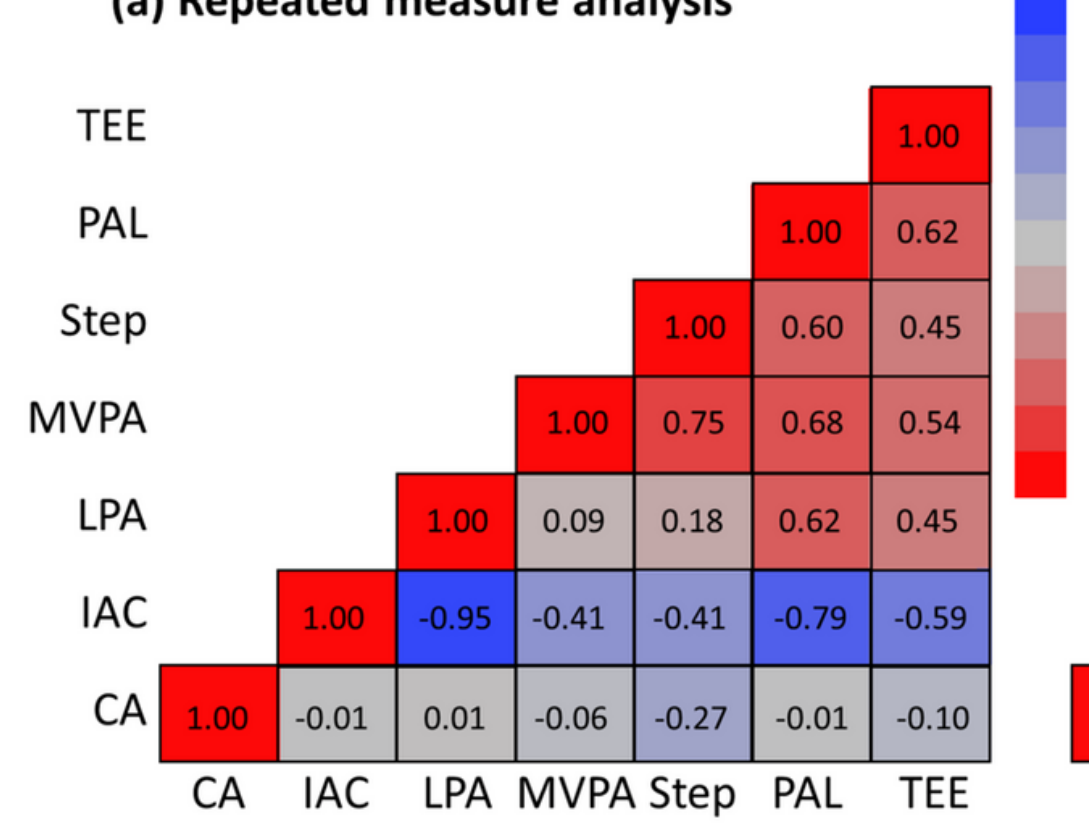

-1 (b) Cross-sectional analysis $-0.8$

$$
-0.6
$$

$-0.4$

$-0.2$

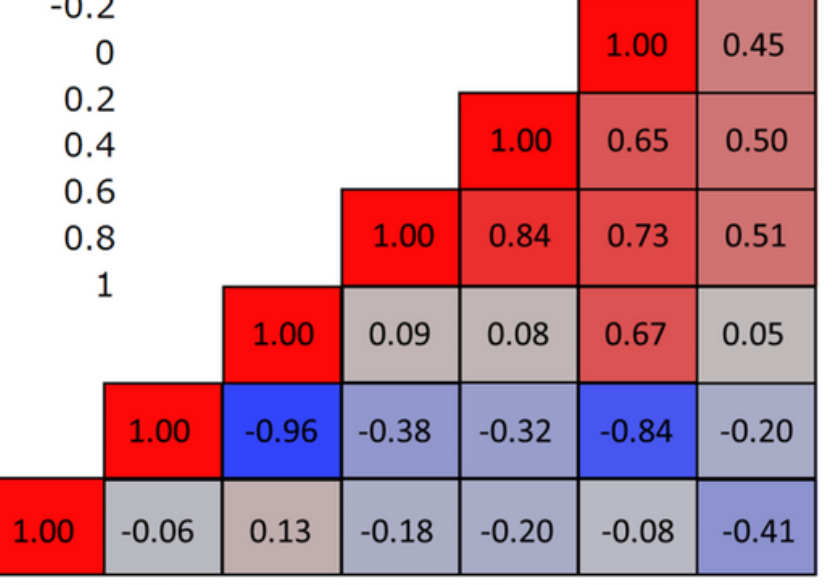

CA IAC LPA MVPA Step PAL TEE

\section{Figure 2}

Comparison of correlation coefficients of physical activity-related variables and chronological age between repeated measurement (a) and cross-sectional data (b) in 689 individuals (3914 measurements) The red and blue panels were expressed as positive and negative correlation coefficients, respectively. CA, chronological age; IAC, inactive time; LPA, low-intensity physical activity; MVPA, moderate-to-vigorous physical activity; PAL, physical activity level; TEE, total energy expenditure.

\section{Supplementary Files}

This is a list of supplementary files associated with this preprint. Click to download.

- Additionalfile1.docx 